\title{
Pengembangan Ekowisata Berbasis Komunitas Pada Objek Wisata Puncak Kuda Sembrani Banjarasri Kulon Progo
}

\author{
Christian Nindyaputra Octarino ${ }^{\# 1}$, Ferdy Sabono ${ }^{\# 2}$ \\ \# Program Studi Arsitektur, Fakultas Arsitektur dan Desain, \\ Universitas Kristen Duta Wacana Yogyakarta \\ ${ }^{1}$ christian.octarino@staff.ukdw.ac.id \\ ²ferdy_sabono@staff.ukdw.ac.id
}

\begin{abstract}
Abstrak - Yogyakarta sebagai salah satu destinasi wisata utama di Indonesia memiliki hampir seluruh potensi wisata baik yang berupa wisata alam maupun buatan. Objek-objek wisata tersebut dapat ditemukan di seluruh penjuru provinsi, termasuk di Kawasan Kulon Progo. Desa Banjarasri, Kalibawang merupakan salah satu daerah yang berpotensi untuk dikembangkan menjadi desa wisata yang mampu menarik aktivitas pariwisata baik lokal maupun nasional. Karakter geografis yang didominasi oleh unsur alam berupa persawahan dan perbukitan menjadikan daerah ini memiliki potensi besar untuk dikembangkan menjadi atraksi ekowisata. Salah satu objek wisata yang ada adalah Puncak Kuda Sembrani, yang menawarkan panorama berupa pemandangan hamparan sawah dengan latar belakang perbukitan yang indah, sejuk, dan menyegarkan mata. Namun diketahui bahwa potensi ini belum dikelola dengan baik sehingga kondisi saat ini dapat dikatakan kurang representatif sebagai sebuah objek wisata. Hal ini ditandai dengan jalur trekking yang sudah hampir tidak terlihat, dan beberapa fasilitas pendukung juga teridentifikasi dalam kondisi tidak layak. Program pengabdian ini bertujuan untuk mengembangkan kembali objek wisata Puncak Kuda Sembrani yang sudah terbengkalai selama beberapa waktu. Metode yang digunakan adalah pengembangan berbasis komunitas, dengan menggandeng tokoh setempat dan juga perwakilan dari kelompok pemerhati pariwisata yang ada di Desa Banjarasri. Bersama dengan masyarakat kemudian dirumuskan ide-ide yang dapat diaplikasikan untuk pengembangan objek wisata Kuda Sembrani seperti desain dan penataan jalur trekking, serta fasilitas pendukung yang dapat memberikan kenyamanan bagi pengunjung sekaligus memberikan pengalaman ekowisata yang berkesan. Melalui program ini diharapkan objek Puncak Kuda Sembrani akan kembali menjadi daya tarik wisatawan yang datang ke Desa Banjarasri.
\end{abstract}

Kata kunci - pariwisata, ekowisata, pengembangan berbasis komunitas, Puncak Kuda Sembrani
Abstract - Yogyakarta as one of the main tourist destinations in Indonesia has almost all tourism potential both natural and artificial tourism. These tourist objects can be found throughout the province, including Kulon Progo area. Banjarasri Village, Kalibawang is one area that has the potential to be developed into a tourism village that can attract tourism activities both locally and nationally. The character of topography which is dominated by natural environment in the form of rice fields and hills makes this area has great potential to be developed as ecotourism. One of the existing attractions is Puncak Kuda Sembrani, which offers a panoramic view of the expanse of rice fields with a beautiful and refreshing hill as a background. However, it is known that this potential has not been managed properly so that the current condition is less representative as a tourist attraction. This is indicated by the almost undefined trekking paths, and some supporting facilities have also been identified as in poor condition. This program aims to redevelop the Puncak Kuda Sembrani tourist attraction which has been neglected. The method used is community-based development, by cooperating with local leaders and also representatives from tourism observer groups in Banjarasri Village. With the community, ideas that can be applied to the development of the Sembrani Horse tourist attraction are formulated, such as the design and arrangement of trekking routes, as well as supporting facilities that can provide comfort for visitors while providing a memorable ecotourism experience. Through this program, it is expected that the Puncak Kuda Sembrani object will again become an attractive tourism object for tourists who come to Banjarasri Village.

Keywords - tourism, eco-tourism, community-based development, Puncak Kuda Sembrani

\section{PENDAhUluan}

Sektor pariwisata menjadi salah satu bidang yang menjanjikan dalam mendukung perekonomian suatu wilayah. Beragam variasi objek wisata terus dikembangkan guna meningkatkan daya tarik wisatawan terhadap daerah 
tersebut. Yogyakarta sebagai salah satu ikon pariwisata di Indonesia seakan tidak pernah berhenti memunculkan objek-objek wisata baru yang selalu mampu menjadi data tarik bagi para wisatawan. Di antara berbagai macam jenis objek wisata yang ada, wisata dengan tema alam dapat dikatakan selalu memiliki daya tarik tersendiri. Karakter alam yang cenderung menyajikan keindahan, kesejukan, dan lingkungan natural dinilai dapat memberikan efek relaksasi lebih bagi pengunjung untuk mengurangi stress. Selain itu wisatawan cenderung mencari suasana yang berbeda dari tempat tinggal atau beraktivitasnya sehari-hari, sehingga wisata alam akan selalu menjadi pilihan [1].

Berbicara tentang wisata alam tentu tidak lepas dari konsep ekowisata, yang menitikberatkan pada pengembangan objek wisata tanpa mengorbankan kualitas dari ekosistem yang ada. Desa Banjarasri Kulon Progo merupakan salah satu desa wisata yang telah menjadi destinasi unggulan sampai di tingkat nasional. Topografi alam berupa hamparan sawah hijau yang dikelilingi oleh perbukitan, ditambah suasana pedesaan yang asri menjadi daya tarik utama yang ditawarkan. Dengan potensi alam yang sedemikian besar, sudah tentu objek wisata dengan tema alam menjadi daya tarik utama yang dapat ditawarkan. Puncak Kuda Sembrani menjadi satu dari sekian objek wisata yang dimiliki oleh Desa Banjarasri. Sesuai dengan namanya, lokasi ini berada di puncak perbukitan yang tentunya menawarkan pemandangan yang indah, sejuk serta menyegarkan. Objek ini wisata ini sudah cukup dikenal luas, hal ini diketahui dari cukup banyaknya informasi yang dapat ditemukan pada laman internet mengenai objek wisata ini baik berupa artikel maupun paket wisata.

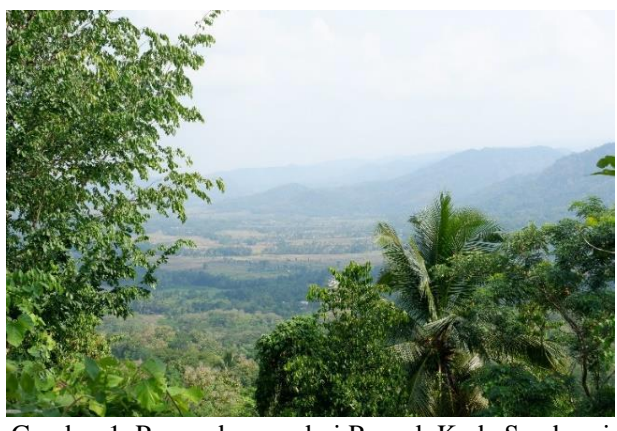

Gambar 1. Pemandangan dari Puncak Kuda Sembrani

Dalam perkembangannya diketahui bahwa objek wisata ini belum terkelola dengan baik, sehingga tidak dapat mengoptimalkan potensi wisata yang ada. Berdasarkan pengamatan dan informasi dari warga setempat, diketahui bahwa kondisi terkini dari Puncak Kuda Sembrani dapat dikatakan tidak layak untuk beroperasi menerima kunjungan wisatawan, baik secara kualitas infrastruktur maupun manajemen pengelolaannya. Program ini merupakan program pendampingan bagi masyarakat untuk dapat mengembangkan kembali objek wisata Puncak Kuda Sembrani sebagai potensi ekowisata agar dapat dinikmati secara optimal bagi para wisatawan. Adapun kegiatan ini menitikberatkan pada hal-hal yang mencakup elemen fisik, diawali dari identifikasi permasalahan dan merumuskan strategi pengembangan.

\section{TINJAUAN EKOWISATA BERBASIS KOMUNITAS}

Pengertian ekowisata yang dikutip dari Peraturan Menteri Dalam Negeri Nomor 33 Tahun 2009 adalah "kegiatan wisata alam di daerah yang bertanggungjawab dengan memperhatikan unsur pendidikan, pemahaman, dan dukungan terhadap usaha-usaha konservasi sumberdaya alam, serta peningkatan pendapatan masyarakat lokal" [2]. Konsep ekowisata sendiri merupakan salah satu upaya pengembangan jenis kegiatan wisata yang melihat lingkungan alam sebagai basis perencanaan sumberdaya yang perlu untuk dijaga dan dilestarikan. Meskipun kegiatan pelestarian digabungkan dengan aktivitas wisata namun perencanaan yang tepat dan strategis akan mendatangkan dampak positif maupun keuntungan bagi lingkungan dan seluruh pelaku wisata didalamnya. Salah satu dampak positif yang dihasilkan dari pengembangan kawasan berbasis ekowisata adalah keseimbangan antara kegiatan wisata dengan kondisi alam yang terjaga, sehingga menjadi magnet bagi para wisatawan [3]. Untuk itu, perencanakaan kawasan dengan pendekatan ekowisata perlu memperhatikan prinsip dan kriteria dalam pengelolaannya agar mendatangkan keuntungan yang diharapkan bersama. Dalam penenarapan ekowisata, terdapat beberapa prinsip dan kriteria seperti kesesuaian antara jenis dan karakteristik ekowisata; bersifat berkelanjutan, pelestarian lingkungan, memiliki nilai edukatif bagi pengunjung serta memberikan manfaat bagi masyarakat secara ekomoni sehingga dalam pemanfaatannya, masyarakat perlu dilibatkan dalam perencanaan kegiatan pengembangan wisata.

Keterlibatan masyarakat menjadi salah satu kriteria wajib sebagai pengendali pengelolaan wisata. Asy'ari, R., dkk (2016), menyebutkan bahwa jika masyarakat dilibatkan dalam pengelolaan ekowisata maka kelestarian dan kesejahteraan lingkungan alam akan tercapai sebagai upaya pemanfaatan potensi alam untuk kebutuhan saat ini maupun untuk jangka Panjang [4]. Lanjutnya bahwa ekowisata berbasis masyarakat menurut WWF-Indonesia (2009) merupakan kegiatan berbasis ekonomi wisata yang melibatkan partisipasi dan peran aktif dari komunitas (masyarakat) pada perencanaan, pelaksanaan, pengelolaan seluruh aspek ekowisata. Keuntungan yang diperoleh dari kegiatan ekowisata berbasis komunitas adalah memberikan manfaat ekologi, sosial dan ekonomi yang besar bagi masyarakat [5]. Pendekatan pengembangan ekowisata ini menggunakan sumber daya lokal, baik alam maupun sosial, untuk mendatangkan keuntungan tidak hanya keuntungan ekonomi namun pengendalian pada keberlanjutan ekosistem di masa mendatang.

\section{METODE PELAKSANAAN}


Program ini pada dasarnya menggunakan metode partisipatori, di mana warga setempat memiliki peran sebagai subjek utama, bukan sekedar menjadi objek. Artinya setiap tahapan kegiatan yang dijalani selalu melibatkan partisipasi aktif dari masyarakat. Hal ini sejalan dengan prinsip ekowisata itu sendiri yang menekankan pada keberlanjutan baik pada aspek lingkungan, ekonomi, dan social [6]. Dengan metode partisipatori diharapkan ide-ide pengembangan akan muncul dari masyarakat dan akan dijalankan dan dikelola oleh masyarakat itu sendiri. Peran dari tim pendamping adalah sebagai fasilitator, dan juga sebagai pemantik untuk memancing pemikiran-pemikiran yang dimiliki oleh masyarakat. Dalam kasus ini, metode pelaksanaan kegiatan terdiri dari observasi bersama dan forum group discussion.

Observasi dan survey lapangan dilakukan pada tahap awal, untuk mengidentifikasi secara lebih spesifik mengenai kondisi terkini dari Puncak Kuda Sembrani, khususnya terkait dengan kondisi infrastrukturnya. Forum group discussion (FGD) dilakukan dalam beberapa sesi, tahap awal untuk pembahasan hasil observasi dan menampung ide-ide pengembangan, tahap selanjutnya adalah pembahasan rencana pengembangan yang akan diterapkan. Inisiatif dan parsitipasi aktif dari masyarakat menjadi kunci kesepakatan bersama yang kemudian menjadi embrio pengembangan berkelanjutan [7].

\section{PEMBAHASAN}

Kegiatan pengabdian masyarakat yang dilakukan di Desa Banjarsari dilakukan dengan beberapa tahapan

\section{A. Tinjauan Lokasi}

Desa Banjarsari merupakan salah satu kelurahan di Kecamatan Kalibawang Kabupaten Kulon Progo Propinsi Daerah Istimewa Yogyakarta. Secara administrasi, sebelah Utara berbatasan dengan Desa Banjaroyo dan Desa Banjarharjo, sebelah Timur berbatasan dengan Sungai Progo dan Kecamatan Minggir. Sedangkan sebelah Selatan berbatasan dengan Desa Banjararum dan pada sebelah Barat berbatasan langsung dengan Desa Sidoarjo dan Desa Purwoharjo. Dikutip dari website desa (http://banjarsarikulonprogo.desa.id), info data statistik jumlah penduduk di Desa Banjarsari adalah berjumlah 203 orang yang terdiri dari 126 laki-laki dan 77 perempuan dengan jumlah pengunjung per hari berada pada kisaran $30-50$ orang per hari.

Adapun penggunaan lahan di Desa Banjarasri secara umum berdasarkan penelitian yang dilakukan oleh L.A Hutapea, Elizabeth (2014) secara umum lahan digunakan untuk fungsi pertanian seperti sawah dan ladang [8]. Sedangkan penggunaan lahan non pertanian antara lain permukiman, pekuburan, pertokoan, perkantoran, pasar, dan sebagainya

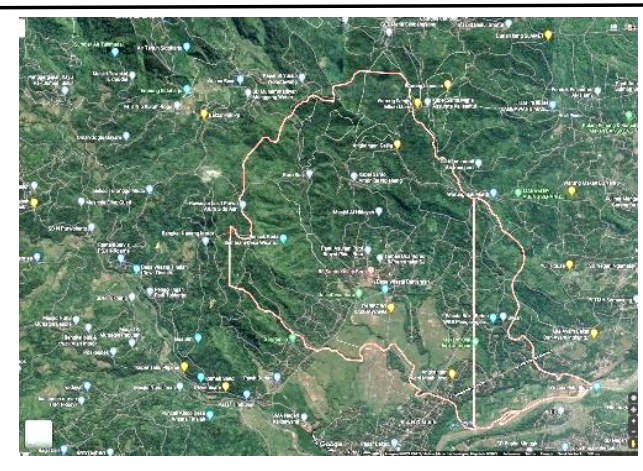

Gambar 2. Peta Desa Banjarsari

Desa Banjarsari memiliki sumber daya wisata alam yang potensial untuk dikembangkan menjadi objek wisata yang menjadi daya tarik bagi wisatawan. Salah satu objek wisata yang menjadi perhatian dalam kegiatan pengabdian masyarakat ini adalah pada pengembangan objek wisata puncak kuda sembrani dengan pendekatan konsep ekowisata. Puncak kuda sembrani merupakan salah satu objek wisata yang sebelumnya telah diupayakan untuk dikelola oleh masyarakat lewat pengadaan jalur (tracking) wisata dan fasilitas pendukung lainnya seperti beberapa lokasi foto bagi wisatawan, namun saat ini kondisi fisik dan ketersediaan fasilitas terlihat kurang terawat bahkan mengalami kerukasan. Seperti pada bangunan posko yang berfungsi sebagai bangunan penerima bagi wisatawan, terlihat tidak terawat serta dalam kondisi kurang layak sebagai fasilitas wisata. Selain itu, kondisi jalur menuju puncak Kuda Sembrani yang cukup curam memberikan ancaman keselamatan bagi wisatawan, terlihat tidak ada pengaman berupa railing pada jalur pendakian sehingga memiliki resiko kecelakaan yang tinggi.

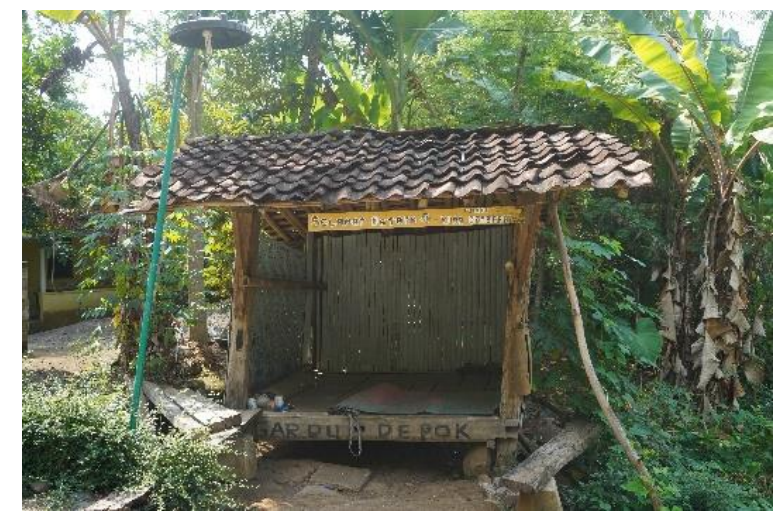

Gambar 3. Bangunan posko penerima wisatawan Kuda Sembrani yang terlihat tidak terawat dengan kurang layak. 


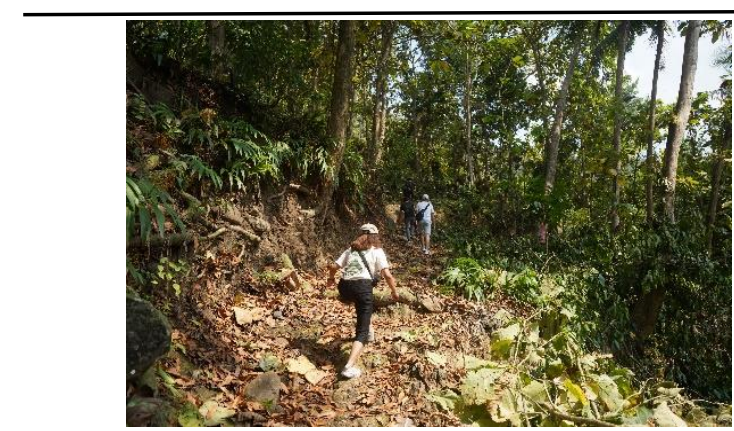

Gambar 4. Jalur track mencapai puncak Kuda Sembrani yang sangat curam tanpa dan cukup berbahaya bagi wisatawan.

\section{B. Persiapan dan Pelaksanaan Kegiatan}

Kegiatan pengabdian masyarakat yang dilakukan di Desa Banjarsari dilakukan dengan beberapa tahapan seperti tahapan persiapan dan tahapan pelaksanaan. Persiapan yang dilakukan antara lain mempersiapakan kebutuhan yang diperlukan dalam melakukan pengamatan (observasi) lapangan. Pengamatan langsung bertujuan untuk memperoleh data-data lapangan sebagai informasi untuk menyampaikan permasalahan dan usulan kepada masyarakat dalam konsep pengembangan ekowisata Puncak Kuda Sembrani yang relevan. Pelaksanaan kegiatan antara lain melibatkan masyarakat dalam penyusunan ide atau gagasan agar tercapainya tujuan partisipasi masyarakat sebagai pihak yang nantinya akan mengontrol pelaksanaan kegiatan pariwisata di Kuda Sembrani.

Berikut adalah beberapa rangkaian tahapan yang dilakukan dalam penyusunan konsep ekowisata di Kuda Sembrani, Desa Banjarsari sebagai berikut;

\section{- Persiapan dan Pengamatan Lapangan}

Persiapaan dilakukan oleh tim pengabdian masyarakat yang tentunya didahului dengan koordinasi bersama pihak setempat (perangkat desa) untuk membantu mengidentifikasi kebutuhan secara general agar mempermudah tim dalam memahami konteks permasalahan awal. Selanjutnya dilakukan pengamatan lapangan untuk mengidentifikasi permasalahanpermasalahan secara lebih spesifik seperti; ketersediaan infrastruktur fisik wisata, potensi wisata yang belum optimal, maupun hal-hal lain yang menjadi kelemahan yang menghambat perencanaan maupun potensi yang dapat disinergikan untuk perencanaan kedepannya. Survei dilakukan pada Minggu 13 Juni 2021 dengan menggunakan peralatan seperti; peralatan tulis, peta dasar, kamera, meteran dan drone.

- Olah Data dan Studi Literatur tentang Ekowisata.

Setelah melakukan pengamatan lapangan, data-data identifikasi kemudian dijadikan sebagai informasi untuk digunakan sebagai temuan untuk disampaikan dan didiskusikan dengan masyarakat. Untuk memperkuat argumentasi sekaligus memberikan gambaran yang lebih luas kepada masyarakat tentang konsep pengembangan ekowisata, maka tim melengkapi data dengan menambahkan studi literatur maupun studi preseden.

- FGD (Focus Group Discussion) sebagai bentuk Keterlibatan Komunitas.

Kegiatan FGD dilakukan dengan menghadirkan 8 (delapan) perwakilan masyarakat, jumlah ini disesuaikan saat kondisi Pandemi COVID -19 sehingga terjadi pembatasan jumlah peserta FGD. Berdasarkan hasil FGD, masyarakat mengharapakan bahwa ada perencanaan yang matang dan terkonsep pada pengembangan wisata di Kuda Sembrani. Masyarakat juga menyampaikan permasalalahan terkait ketersediaan infrastruktur, dukungan ekonomi serta dukungan dalam hal desain yang saat ini menjadi kendala. Hasil FGD memebrikan gambaran bagi tim PKM untuk memetakan kembali permasalahan dan potensi sebagai upaya untuk membantu masyarakat dalam perencanaan.

\section{- Luaran berupa Olah Desain}

Luaran dari kegiatan PKM ini adalah memberikan desain panduan (guidelines) yang bertujuan untuk memberikan konsep pengembangan yang relevan berdasarkan kebutuhan dan kriteria-kriteria yang diusulkan oleh masyarakat. Desian panduan yang dimaksudkan adalah memetakan kembali jalur trekking wisata di Kuda Sembrani untuk memudahkan perencanaan infrasturktur berupa penataan pathways (jalur jalan) dari posisi posko hingga puncak sembrani yang menjadi destinasi akhir bagi wisatawan. Selain itu, peta identifikasi tentang kondisi kontur yang menjadi kriteria ataupun pertimbangan dalam menentukan amenitas (pelayanan) bagi wisatawan seperti rest area ataupun spot-spot strategis. Pemetaan ini juga dimaksudkan agar memudahkan masyarakat dalam melakukan pengembangan ke depannya dalam konteks ekowisata, seperti pemahaman akan kondisi topografi (kontur) akan membantu masyarakat dalam mendesain lahan (mengurangi intervensi pada lahan), ataupun usulan penggunaan material dan bahan-bahan alam (seperti bambu dan kayu) dalam mendesain alur trekking agar memberikan nuansa alam yang tetap asri serta meminimalisir pemangkasan atau pemotongan vegetasi eksisiting.

\section{Usulan Konsep Pengembangan}

Berdasarkan hasil pengamatan langsung pada objek wisata Puncak Kuda Sembrani dan melalui diskusi dengan masyarakat setempat, maka dapat diketahui bahwa memang objek wisata ini sedang berada dalam kondisi "tidak layak" untuk dikunjungi. Kondisi yang dimaksud tidak berkaitan dengan pada potensi, namun pada kualitas infrastruktur pendukungnya. Ditinjau dari unsur utama 
pariwisata yaitu attraction (atraksi), amenity (amenitas), accessibility (aksesibilitas), dan anciliary (fasilitas pendukung), objek wisata Puncak Kuda Sembrani sudah memiliki potensi besar pada atraksi dan amenitas, namun masih lemah pada aksesibilitas dan fasilitas pendukung. Dengan medan yang cukup berat dan ekstrim, perlu adanya perencanaan yang matang untuk dapat menjamin kenyamanan dan keamanan pengunjung. Beberapa poin utama dalam pengembangan objek wisata ini di antaranya pengembangan masterplan objek wisata, desain jalur trekking, dan pengembangan fasilitas pendukung.

Pengembangan masterplan mencakup penataan akses kedatangan dan aktivitas pengunjung, serta penempatan fasilitas pendukung. Dengan jarak tempuh sekitar $900 \mathrm{~m}$, maka perlu adanya perencanaan titik-titik pemberhentian bagi pengunjung yang ingin beristirahat sejenak. Dengan jarak tempuh ideal pejalan kaki sejauh kurang lebih 250 $300 \mathrm{~m}$ untuk iklim tropis, maka ditentukan adanya dua titik peristirahatan. Jarak antar titik istirahat ditentukan berdasarkan kondisi topografi dari jalur yang ditempuh.

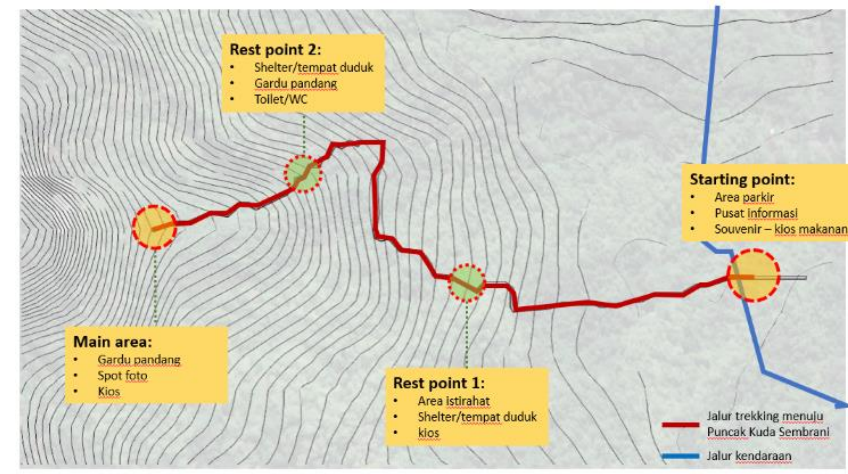

Gambar 5. Rencana penataan jalur Puncak Kuda Sembrani

Aksesibilitas menjadi perhatian utama pada objek wisata Puncak Kuda Sembrani. Dengan kontur jalur yang cukup ekstrim, perlu adanya infrastruktur yang memadai agar akses pengunjung menuju puncak dapat lebih mudah. Hal ini diupayakan agar target pasar untuk objek wisata ini dapat lebih diperluas, tidak hanya sebatas pada kalangan tertentu. Terlebih karakter trekking seperti ini cukup populer bagi para wisatawan karena dianggap dapat berwisata sekaligus berolahraga [9] Secara garis besar, jalur menuju Puncak Kuda Sembrani dapat dibedakan menjadi 3 segmen dengan tingkat kemiringan kontur yang berbeda. Prinsip dasar dari pengembangan jalur trekking ini adalah meningkatkan aksesibilitas sehingga jalur dapat dilalui dengan lebih nyaman dan aman. Sebagaimana diketahui bahwa keamanan merupakan salah satu aspek penting yang dapat mempengaruhi minat wisatawan berkunjung ke sebuah objek wisata [10]. Beberapa konsep yang bisa diterapkan adalah sebagai berikut:

- Memperjelas rute/jalur yang dilalui, dengan memberikan perbedaan material pada jalur yang digunakan. Material ini dapat berupa deck kayu, bambu, atau material lain yang dapat ramah terhadap lingkungan

- Menambahkan railing/pegangan terutama pada jalur yang berada di area kontur yang ekstrim

- Menambahkan elemen-elemen penunjuk arah untuk menghindari terjadinya pengunjung yang tersesat
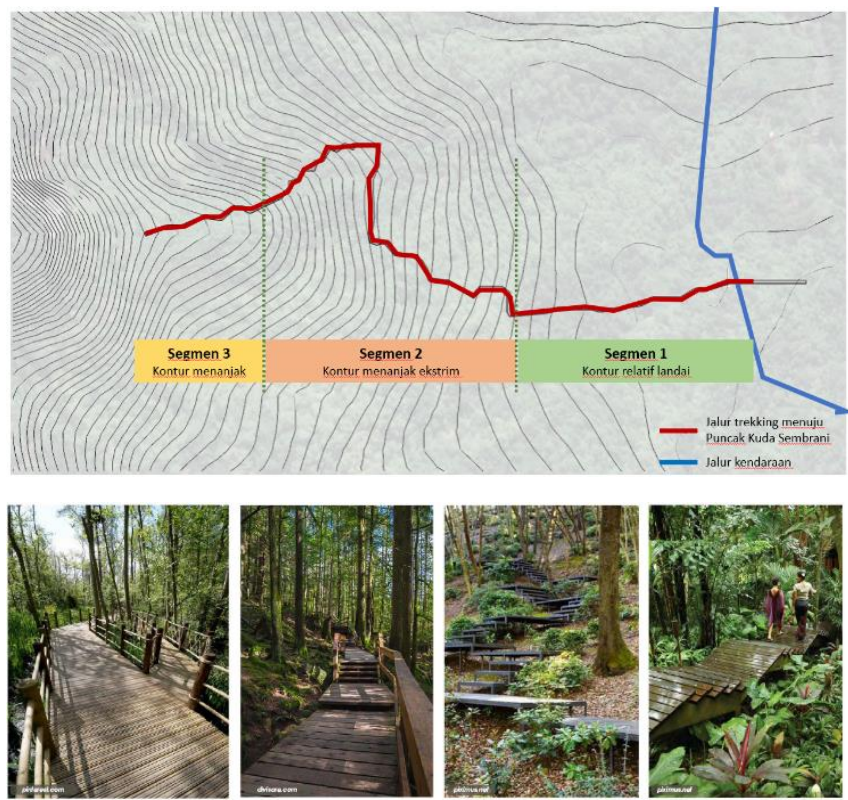

Gambar 6. Pembagian segmen jalur dan Ilustrasi pengembangan jalur trekking

Poin ketiga terkait fasilitas pendukung yang kurang memadai secara kuantitas maupun kualitas. Fasilitas pendukung yang dikembangkan sesuai dengan fungsifungsi yang telah disebutkan pada bagian penataan area objek wisata. Fungsi tersebut di antaranya adalah: area ticketing, kios makanan dan souvenir, tempat duduk/istirahat, toilet umum, dan gardu pandang. Desain yang diterapkan untuk fasilitas-fasilitas ini adalah desain yang bernuansa alam, sehingga pengunjung tidak akan kehilangan atmosfer natural yang dirasakan sembari beristirahat dan menikmati pemandangan sekitar. Penekanan pada nuansa alam dapat dicapai melalui penggunaan material dan juga karakter dari ruang-ruang yang terbentuk, yang didesain agar tetap menghadirkan bahkan memperkuat suasana hijau dan natural pada Kawasan tersebut. 

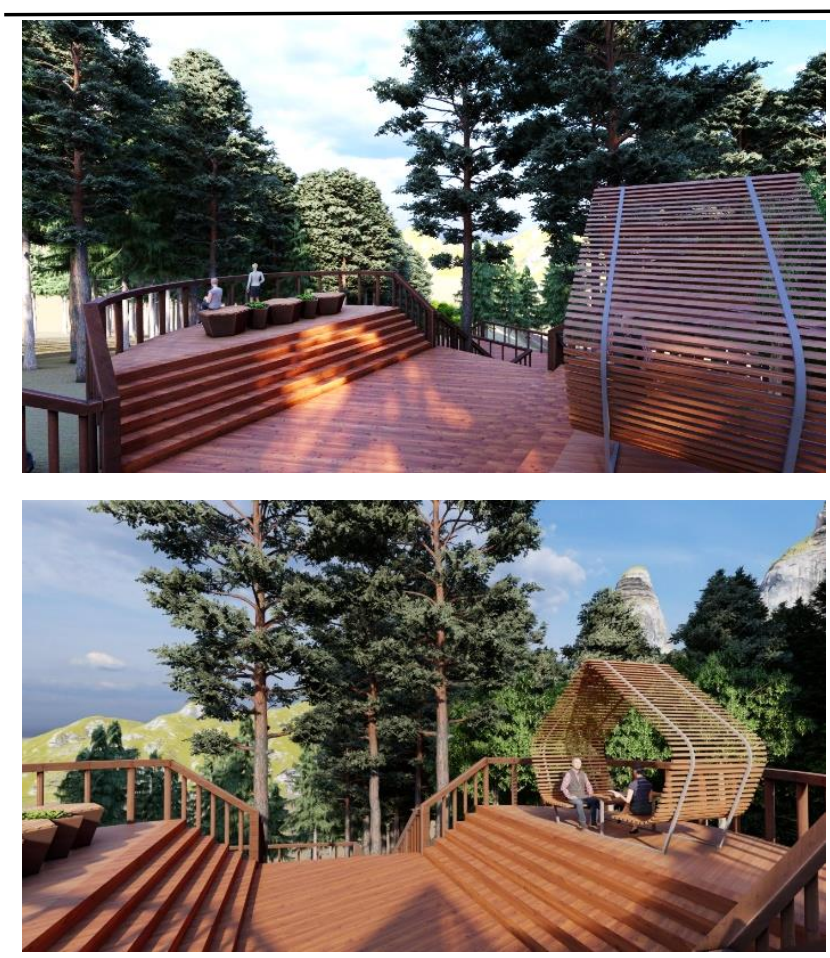

Gambar 7. Ilustrasi usulan desain untuk titik istirahat dan gardu pandang

\section{KESIMPULAN}

Sebagai potensi wisata unggulan, Puncak Kuda Sembrani memiliki cukup banyak aspek yang perlu dikembangkan. Dalam kasus ini, partisipasi aktif dari masyarakat memiliki peranan penting dalam upaya menghidupkan serta mengembangkan kembali objek wisata Puncak Kuda Sembrani, baik pada tahap observasi dan juga merumuskan strategi-strategi pengembangan. Hal ini sejalan dengan konsep utama yang ditetapkan, yaitu pengembangan ekowisata yang berkelanjutan. Strategi-strategi yang dirumuskan akan dibagi menjadi strategi jangka pendek dan jangka Panjang. Diharapkan masyarakat dapat melanjutkan secara mandiri baik pengelolaan maupun pemeliharaan objek wisata Puncak Kuda Sembrani sehingga dapat selalu optimal memberikan pengalaman wisata bagi para pengunjung.

\section{UCAPAN TERIMA KASIH}

Penulis mengucapkan terimakasih kepada Lembaga Penelitian dan Pengabdian pada Masyarakat (LPPM) serta Fakultas Arsitektur dan Desain Universitas Kristen Duta Wacana Yogyakarta atas segala bentuk dukungan yang diberikan sehingga seluruh rangkaian kegiatan dapat terlaksana dengan baik.
DAFTAR PUSTAKA

[1] W. Kastolani, S. Marhanah and G. Fauzan, "Hubungan Daya Tarik WIsata dengan Motivasi Berkunjung Wisatawan ke Alam Wisata Cimahi," Jurnal Manajemen Resort dan Leisure, vol. 13, no. 1, pp. 36-43, 2016.

[2] "Peraturan Menteri Dalam Negeri Nomor 33 Tahun 2009 Tentang Pedoman Pengembangan Ekowisata di Daerah".

[3] M. Pattiwael, "Konsep Pengembangan Ekowisata Berbasis Konservasi di Kampung Malagufuk Kabupaten Sorong," $J$ DEPACE (Journal of Dedication to Papua Community), vol. 1, no. $1,2018$.

[4] R. Asyaril, R. Dienaputra, A. Nugraha, R. Tahir, C. U. Rahman and R. R. Putra, "Kajian Konsep Ekowisata Berbasis Masyarakat dalam Menunjang Pengembangan Pariwisata: Sebuah Studi Literatur," Pariwisata Budaya: Jurnal Ilmiah Agama dan Budaya, vol. 6 , no. $1,2021$.

[5] H. Faizi, B. Ulumi and M. Syafar, "Pengembangan Ekowisata Pulau Tunda Berbasis Komunitas dalam era Industri 4.0," Jurnal Antropologi: Isu-Isu Sosial Budaya, vol. 23, no. 1, pp. 118-128, 2021.

[6] R. Pakpahan, "IMPLEMENTASI PRINSIP PARIWISATA BERBASIS KOMUNITAS DI DESA WISATA NGLINGGO YOGYAKARTA,” Jurnal Master Pariwisata (JUMPA), vol. 5, no. 1, pp. 129-146, 2018.

[7] G. Handajani and S. Sariffuddin, "MENGATUR DESA WISATA: PERAN TOKOH MASYARAKAT MEMBANGUN INISIATIF KOLEKTIF DALAM PENGEMBANGAN PARIWISATA BERBASIS KOMUNITAS," Tata Loka, vol. 20, no. 2, pp. 195204, 2018.

[8] E. L. Hutapea, "Perubahan Tata Ruang Rumah dan Lingkungan di Desa WIsata Banjarasri Kulon Progo Yogyakarta," Perpustakaan Magister Arsitektur UNDIP, 2014.

[9] S. Hidayat, W. Danardani and N. P. D. S. Dartini, "Pendampingan Penyusunan Aktivitas dan Promosi Trekking di Pokdarwis Puncak Landep Desa Panji Anom," in Proceeding Senadimas Undiksha, 2020.

[10] P. M. N. Sondakh and A. Tumbel, "Pelayanan, Keamanan, dan Daya Tarik Mempengaruhi Minat WIsatawan yang Berkunjung ke Objek WIsata Alam Gunung Mahawu, Tomohon," Jurnal Berkala Ilmiah Efisiensi, vol. 16, no. 1, pp. 280-288, 2016. 